NOWA KODYFIKACJA PRAWA KARNEGO Tom LX

NEW CRIMINAL LAW CODIFICATION

AUWr No 4039

Wrocław 2021

https://doi.org/10.19195/2084-5065.60.4

\title{
Handwriting analysis as an assessment instrument in legal psychology
}

\author{
YURY CHERNOV \\ ORCID: 0000-0002-4137-0660 \\ IHS Institute for Handwriting Sciences, Zurich, Switzerland

\section{VALI ENGALYCHEV} \\ Tsiolkovskiy Kaluga State University, Kaluga, Russia
}

\begin{abstract}
Handwriting analysis has several advantages important for legal psychology over traditional instruments. However, being a projective method, it must be well validated. The article presents a formal system of psychological handwriting analysis, which allows an objective and transparent procedure and in particular ensures conditions for proper validation. Practical examples demonstrate that.
\end{abstract}

Keywords: handwriting psychology, formal handwriting analysis, computer application, legal psychology, validation

\section{Introduction}

Legal psychological examination is a field which especially requires objective and reliable methodological tools: the responsibility of an expert is very high. This expertise area is the generalisation of two fields: forensic and criminal psychology. ${ }^{1}$ Criminal psychology is mainly to do

${ }^{1}$ D. Howitt, Introduction to forensic and criminal psychology, Harlow 2018. 
with psychological aspects of criminal behaviour by individual persons and groups. This generally includes the origins and development of criminality. Forensic psychology deals mainly with courts and law - that is, with trials. However, it should be understood more widely. It includes all possible aspects of the legal system: investigation, policing, prisons, etc. It is applicable to criminal, civil, and family contexts. The objects of forensic psychology may be criminals, suspects, witnesses, family members, investigators, detectives, prosecutors, lawyers, experts, etc.

Generally, legal psychological assessment uses the same methods and instruments as other application fields of psychology. However, it has strong specifics. First, often an explicit involvement of the person under investigation or expert evaluation is not possible. The person is simply not available or refuses to participate in the testing. Second, the information from a person under investigation is not credible - the person would just manipulate their answers.

That is why alternative or additional methods, which could enhance the level of objectivity and credibility, are very important. One of such instruments is handwriting psychology. Previously known as graphology, it has been developed and used for decades and has a long path of experiences. It provides a wide coverage of personal characteristics and excludes social desirability, the latter being one of the major problems of psychometric instruments, especially questionnaire-based tests. However, traditional graphology lacks sufficient validation. ${ }^{2}$ Computer-based instruments and the newly developed methods of formalised handwriting analysis demonstrate new promising validation results. ${ }^{3}$

In the current article, we are presenting some examples of handwriting psychology application. Generally, it can be used in different fields of legal assessment: ${ }^{4}$

2 T. Chamorro-Premuzic, A. Furnham, The psychology of personnel selection, Cambridge 2014; U.P. Kanning. Standards der Personaldiagnostik, Hogrefe 2019.

3 Y. Chernov, "Formal validation of handwriting analysis", [in:] Handwriting research: Validation \& quality, Berlin 2018, pp. 37-68.

4 V. Engalychev, "The place of handwriting analysis in legal psychology: Topical issues and research perspectives", Aspects of Handwriting 2020, no. 2, pp. 3-20. 
1. criminal psychology - identifying typical patterns of criminal behaviour in general and leaders of criminal groups in particular; psychological specifics of criminals with different ethno-social backgrounds;

2. preventive psychology - identifying psychopathological potential in at-risk zone individuals; revealing anti-criminal and/or prosocial tendencies in suspect persons;

3. investigative psychology - classical (trace) psychological profiling; distant psychological profiling; detecting psychological specifics of different investigation participants (suspects, investigators, witnesses, etc.);

4. penitentiary psychology - evaluating the efficiency of specific punishment; psychological evaluation of correction dynamics and re-education efficiency.

Handwriting psychology covers many aspects of personality. Thus, in the mentioned areas it can supplement traditional instruments in various tasks a criminal or forensic psychologist faces. That includes, for instance:

1. in-person psychological forensic examination - psychological handwriting analysis supplements and specifies the list of characteristics obtained with the help of a standard psychological examination;

2. psychological forensic assessment in absentia - allows obtaining some unique psychological information about the personality under examination (usually done on suicides who left notes, letters, diary entries, etc. or regarding missing people);

3. non-forensic expert examinations conducted at lawyers' and human rights defenders' requests have become an important trend in the application of psychological handwriting analysis in recent years; examining handwritten materials of the surrender and first confessions often reveals indications of inadequate mental state of the subject that may point to them being under an illegal psychological impact;

4. criminal profiling enables the linking of an individual's action to its psychological profile; a person's handwriting can be one of the important information sources when others are hardly available. In particular, profiling is most often used to identify potential or acting terrorists, paedophiles, criminals demanding ransom for kidnapped people, etc. In this case, psychological examination is based on the traces left at the crime scene; 
5. distant profiling allows the use of psychological handwriting analysis along with other techniques and methods such as analysis of video records, photographs, audio recordings, witness testimonies, video surveillance, etc. This results in building psychological portraits of criminal gang leaders, corruptionists, and others who are not available for a regular psychological examination.

The mentioned implementation areas are promising. However, they can be successfully realised only if handwriting psychology answers the requests to improve the quality and the validation process. That is possible only with formalised and clear procedures. In the current article, we consider in particular the computer system HSDetect, developed at Zurich Institute for Handwriting Sciences.

\section{Method: Handwriting psychology}

Before we describe the formalisation of handwriting analysis, let us compare the traditional psychometric instruments used for it (mainly questionnaires, for instance, NEO-FFI for big five, or 16PF for Cattel's scales). That allows to see its advantages and drawbacks as well as emphasise the improvement guaranteed by the formalised approach.

1. A typical psychometric test detects only separate psychological characteristics of a person. Handwriting psychology covers wide aspects of personality, so many psychological traits in one procedure. This includes the spheres of emotion, vitality, motivation, social, communication, mental, working, personal attitude, self-concept, and self-esteem.

2. A psychometric test presents a self-image of the persons who answer questions about themselves. Handwriting psychology is an external image and from this point of view can be considered more objective.

3. Psychometric tests are strongly influenced by the social desirability of the given answers. People mostly know what "the correct answers" are, especially when they are under expertise or during a recruiting process. Handwriting psychology makes it possible to completely exclude social desirability. The average person does not know how to manipulate their handwriting to get better assessment results.

4. A psychometric test typically is heavily language-dependent. In every country, it must be adapted to the local cultural environment. Hand- 
writing psychology works with any European language without special adaptation. An expert can analyse specimens in an unknown language.

5. Any test requires a special test-session, so an exam situation of a sort. This makes people feel stressed, which can influence the answers and thus the result. Handwriting, to the contrary, is a natural process. Additionally, we can use previously written texts for the analysis, i.e. texts written in a normal situation, unrelated to the investigation.

Along with these advantages, traditional graphological analysis has some commonly known problems. First, it is less structured than a typical psychometric test. Both the process and the result report strongly depend on the expert. The report typically has the form of a plaintext, which can be ambiguously interpretable. Secondly, the whole graphological analysis procedure is not transparent. Thirdly, classical graphology is purely validated, which is mentioned in multiple publications on the topic (most commonly referred to). ${ }^{5}$

Handwriting psychology, especially the formalised computer-aided approach, makes it possible to overcome the mentioned issues. Through it handwriting analysis becomes more structured and transparent. This can be achieved in particular through mathematical modelling. This approach

5 G. Ben-Shakhar et al., "Can graphology predict occupational success? Two empirical studies and some methodological ruminations", Journal of Applied Psychology 74, 1986, no. 4, pp. 645-653; H.J. Eysenck, G. Guidjonsson, "An empirical study of the validity of handwriting analysis", Personality and Individual Differences 7, 1986, no. 2, pp. 263-264; C. Dazzi, L. Pedrabissi, "Graphology and personality: An empirical study on validity of handwriting analysis", Psychological Reports 105, 2009, no. 3, pp. 1255-1268; A. Furnham, T. Chamorro-Premuzic, I. Callahan, "Does graphology predict personality and intelligence?", Individual Differences Research 1, 2003, no. 2, pp. 78-94; A. Furnham, B. Gunter, "Graphology and personality: Another failure to validate graphological analysis", Personality and Individual Differences 8, 1987, no. 3, pp. 433-435; B. Gawda, "Lack of evidence for the assessment of personality traits using handwriting analysis", Polish Psychological Bulletin 45, 2014, no. 1, pp. 73-79; R.N. King, D.J. Koehler, "Illusory correlation in graphological inference", Journal of Experimental Psychology 5, 2000, no. 4, pp. 336-348; R. Klimoski, A. Rafaeli, "Inferring personal qualities through handwriting analysis", Journal of Occupational Psychology 56, 1983, no. 3, pp. 191-202; E. Netter, G. Ben-Shakhar, "The predictive validity of graphological inferences: A meta-analytic approach", Personality and Individual Differences 10, 1989, no. 7, pp. 737 745; R. Vestewig, M. Moss, "On the validity of graphoanalysis", Journal of Personality Assessment 41, 1977, pp. 589-600. 
is supported by the authors of the present article. Below we briefly describe the proposed mathematical model.

It is more complicated with validation. The lack of proper handwriting analysis validation is true, or at least partly true. Typically, the authors of critical works refer to the same old studies and meta-analyses. However, as was shown in our analysis, ${ }^{6}$ these studies have serious methodological problems.

- Validation analysis is based on ambiguously interpretable free-style text graphological reports; this often takes place in validation studies, which involve graphologists.

- Improper handwritten specimens are used - they are too short or written with instruments improper for the handwriting analysis, such as ones with soft tips.

- Researchers evaluate handwriting samples themselves, without relevant training. They often draw their conclusions based on primitive graphological books, plenty of which are available.

- Improperly modelled test scales. In the validation studies, which compare handwriting analysis to psychometric tests, the scales of the tests are too simplified.

- Only several handwriting signs are considered because they are the simplest. Researchers ignore many important and relevant handwriting signs - that mostly happens when they evaluate the handwriting samples themselves.

- Validation experiments are poorly planned or too complicated and confusing.

- Poor statistical data and methods. In most cases, researchers use only straightforward Pearson correlation to check their handwriting analysis results against psychometric tests. Often the simple comparison would not work because the distribution of variables is not normal, the results are not measured on the continuous scale, etc. Besides, since the evaluation of handwriting is time-consuming and requires much effort, only a restricted amount of statistical data is available. That could be fine in a pilot study. However, the conclusions about the quality of handwriting analysis in general are not appropriate in these cases.

6 Y. Chernov, op. cit. 
- Subjectivity, prejudiced and biased approach. Often researches build their experiments around the opinion they already hold. They want to prove either uselessness or usefulness of the chosen method. In many studies one can see that this strongly influences the interpretation of the results.

This list of typical problems is merely a summary - more details and references to specific examples can be found in Formal validation of handwriting analysis. The vast majority of known studies have one or several problems. Due to that, we can draw no substantial scientific conclusions out of these studies.

We can state that there is not enough proof of validity, but there is also no reason to state that handwriting psychology in general is invalid. Validation should be evaluated by experiments that comply with quality requirements. This is possible with a clear formalised model of handwriting analysis and comprehensive, reproducible interpretation. That distinguishes handwriting psychology from graphology. Finally, we need an effective computer application and enough statistical data. Some promising results, including those in legal psychology, have been achieved with the HSDetect system.

\section{Method: Formalized handwriting analysis with HSDetect}

HSDetect is a computer system for handwriting analysis (by "handwriting analysis" we mean handwriting psychology and traditional forensic handwriting analysis for author identification). It includes several databases and a programming block. ${ }^{7}$ Its design is based on the following principles:

- quantitative presentation of all data. That relates both to handwriting signs and psychological traits, as well as to the connections between them;

- statistical integration of different handwriting analysis methods. The models of psychological traits represent the sets of related handwriting signs. These sets were formed on the basis of multiple graphological publications and reflect the statistically accumulated experience. In spite of

7 Y. Chernov, Psychologicheskij analiz pocherka. Sistemnij podhod, Moscow 2011; Y. Chernov, "Der Einsatz des Computers in der Graphologie", Angewandte Graphologie und Persönlichkeitsdiagnostik 2014, no. 2, pp. 18-37. 
known validation problems, we should not forget that graphologists, who are often psychologist or physicians, made many interesting observations and summaries on the basis of their practical work. We should not simply ignore them - rather we should be very careful and critically validate their findings;

- a formal unambiguous definition of handwriting signs, which must be carefully preserved by their manual evaluation. Without this, further statistical calculations make little sense;

- algorithmic evaluation of psychological traits on the basis of manually evaluated handwriting signs. In principle, it would be much preferable to automatically evaluate handwriting signs. However, so far it is not possible. The existing systems can cover only a handful of signs and even then they are rather unreliable;

- open and adaptive character of the system. The existing solution is not a fixed system, but rather a framework. The databases include much data for algorithmic calculations. However, this data is being permanently enriched, partly based on the already done validation experiments.

Psychological handwriting analysis includes three objects: handwriting signs, psychological traits, and the relations between them. The relations are rather complicated: one sign relates to several traits and every trait depends on several signs.

In the HSDetect model, handwriting signs and personality traits are presented as variables on the continuous scale from 0 to 1 . For signs, zero means that it is not present in the analysed handwriting sample, one - that the sign is obviously and strongly present. The analysis of handwriting samples, i.e. quantitative evaluation of handwriting signs, is done manually. To ensure unambiguity, signs (or more precisely: the way they are evaluated) are defined algorithmically. Let us take, for instance, one of the simplest signs - letter size. It is defined as the vertical distance from the lowers point of the letter to its highest point along the letter slope line. Only inner (excluding the first and last letters of a word) letters of the middle zone are considered. That means letters $a, c, e, m, n, o, r, s, u, v, w$. The size of every measured letter can have the following values: very small $(<1.5 \mathrm{~mm})$, small (1.5-2 $\mathrm{mm})$, medium $(2-3 \mathrm{~mm})$, big $(3-5 \mathrm{~mm})$ and very big $(>5 \mathrm{~mm})$. Assume that we measure all corresponding letters in the handwriting sample. Let us denote the number of all inner middle zone letters in the investigated 
handwriting sample as $M$. Then the number of letters of each mentioned size is correspondingly $m_{i}$. The values of handwriting sign "very small" equals $m_{l} / M$, "small" $-m_{2} / M$, "medium" $-m_{3} / M$, "big" $-m_{4} / M$, and "very big" $-m_{5} / M$. The sum of all $m_{i} / M$ naturally equals one. Of course, in the analysed text, you typically do not encounter all possible sizes; typically, it is one or two, sometimes three. That is a theoretical, scientific approach. In practice, an expert will not measure every individual letter, but will use some heuristics. However, the "ideal" algorithm can be considered for the difficult and control cases.

Every trait is modelled as a function of several handwriting signs by means of what we call graphometric functions:

$$
y=\sum_{n} a_{i} \cdot x_{i}
$$

where $y$-the level of the trait; $n$ - number of handwriting signs that indicate the trait; $x_{i}$ - evaluated level of handwriting sign $i ; a_{i}$ - coefficient indicating the weight of handwriting sign $i$ for trait $y$. The coefficients are calculated statistically (the algorithm is not in the scope of the current article). What is important is that the sum of $a_{i}$ equals one.

Additionally, we consider the reliability of the trait evaluation. This reliability is specific for each individual handwriting sample. The more handwriting signs out of those included in the graphometric function are present, the higher the reliability of the evaluation. The final value of the personal trait is modelled as follows:

$$
y=\sum_{n}\left(\left(a_{i} \cdot x_{i}\right)^{\alpha} \cdot\left(1-r^{k}\right)^{1-\alpha}\right)
$$

where $k$ - the number of handwriting signs out of $n$ that are really present, i.e. $x_{i}>0$, correspondingly $k \leq n ; r$ - the assumed probability of a false decision about the trait if we base its identification only on one handwriting sign out of $n$, i.e. only one sign out of $n$ is present in the analysed sample, empirically $r=0.8 ; \alpha$-parameter identifying the trait level weight.

Formula (2) represents the elaborated model (E-model), which is being used for various research, including validation experiments. However, the absolute value of $y$ is not very representative, especially when you want to compare different traits to one another. Traits depend on different handwriting signs and different $n$. That is why, although theoretical value inter- 
vals for all of them are the same - between 0 and 1, the actual intervals are different. Thus, for one trait the value 0.4 might be low, and for another, which actually changes from 0 to 0.5 , it is high. To understand the actual level of a trait, we should convert it from absolute to normalised values. That is possible when we have enough statistical data. The normalised value for a trait can be expressed as follows (in a standard way):

$$
z=(y-Y) / \sigma
$$

where $Y$ is the expected value and $\sigma$ is the standard deviation of statistical row of trait $y$. However, (3) can be used only if the row is normally distributed, which is often not the case. That is why we prefer a heuristic normalisation:

$$
z=\left(y-y^{\min }\right) /\left(y^{\max }-y\right)
$$

In (4) $z$ changes from 0 to 1 and shows how strong the trait is in the investigated person compared to other people (statistical data is retrieved from the HSDetect database).

The model (1)-(4) is used mainly in research and personal assessments, when we need a complete psychological portrait of a person. When investigating a separate personal features it is often enough to evaluate them by a simplified W-model (weighted model) or P-model (plain model). Wmodel includes only (1) and (4). P-model includes (1) and (4), where additionally all $a_{i}=1 / n$ and $x_{i}$ are dichotomous variable with two values: 0 or 1 . In this case, we simply estimate how many handwriting signs out of $n$ are present in the investigated handwriting. Our investigations showed that for the majority of traits the correlation between E-model, W-model, and P-model is strong enough. With some traits, the loss of information when we switch to a simplified model is substantial. In the examples presented in the present article, we can use the simplified models without significant distortion.

HSDetect includes over 700 handwriting signs and about 400 traits in total. The quality of individual trait modelling is different, which is natural for such a complicated system. Some traits are modelled with few handwriting signs, others - with dozens. On average, it is 22 handwriting signs for a trait. HSDetect has been successfully validated in several 
studies against well-known psychometric tests and expert procedures. ${ }^{8}$ The validation results are generally positive; at least they are better than in previously published studies on the same psychometric tests. That is promising, even though it is clear that the modelling of some traits should be additionally investigated and improved.

\section{Results: Exemplary use cases}

To demonstrate the possibilities of the formalised handwriting analysis in legal psychology, we will show two use cases.

\section{Use case 1: Assessment of aggressiveness ${ }^{9}$}

The phenomenon of aggression has always attracted scientists' attention. However, there is a broad diversity of approaches to understanding the psychological origins of aggressive behaviour and forms of aggression. Thus, there is no generally accepted definition of this phenomenon. Some authors ${ }^{10}$ define aggression as any act that harms another individual who is motivated to avoid such harm. This definition is very broad and

8 M.A. Nauer, Y. Chernov, "Psychodynamic diagnostics: Validation research based on computer modelling of handwriting psychology", paper presented at the $13^{\text {th }}$ European Conference on Psychological Assessment (ECPA 13), Zurich, Switzerland, 22-25 July 2015; Chernov Y., "Validation of computer-aided handwriting analysis and its integration into psychological assessment", paper presented at the $15^{\text {th }}$ European Conference on Psychological Assessment (ECPA 15), Brussel, Belgium, 7-10 July 2019; Y. Chernov, C. Caspers, "Formalized computer-aided handwriting analysis: Validation and integration into psychological assessment", paper presented at the XVI European Congress of Psychology, Moscow, Russia, 2-5 July 2019; Y. Chernov, C. Caspers, "Computergestützte Validierung in der Graphologie", Angewandte Graphologie und Persönlichkeitsdiagnostik 2015, no. 2-3, pp. 16-19, 41-53; Y. Chernov, C. Caspers, "Formalized computer-aided handwriting psychology: Validation and integration into psychological assessment", Behavioral Sciences 10, 2020, no. 1; Y. Chernov, "Formal modelling of projective techniques and their validation", paper presented at the $82^{\text {nd }}$ Annual Meeting of the Psychometric Society (IMPS 2017), Zurich, Switzerland, 17-21 July 2017.

9 Y. Chernov, V. Engalychev, "Distant profiling: Aggression evaluation with formalized handwriting analysis", Armenian Journal of Forensic Expertise and Criminalistics 2019, no. 1, pp. 87-95.

10 R.A. Baron, D. Richardson, Human aggression, New York 1994. 
can include a wide range of behaviours, ${ }^{11}$ starting from those that do not include any harmful actions or passive-aggressive behaviours and ending with verbal and physical aggression that inflicts violence. Aggression is traditionally divided into affective (reactive) and instrumental. ${ }^{12}$ The first one is associated with a negative affect, typically anger. The second is usually goal-driven and could be free from affect. The line between these two poles is very blurry.

Aggressiveness is expressed through a conscious or unconscious aspiration of a person to reach their aims and by this possibly cause harm to someone, destroy or damage something.

Aggressive actions are not always caused by the aggressiveness of the individual, and the aggressiveness is not always manifested in clearly aggressive actions. Aggressiveness is seen not only as the tendency of a person to act hostilely and aggressively, but also readiness for aggression. The concept of aggressiveness considers mental phenomena and properties such as motives, ${ }^{13}$ states, personality traits, and temperament, as well as situational and stable forms of human behaviour as features of individuality. Aggressiveness is a relatively stable readiness for aggressive actions in various situations and should be understood as a personality trait.

In forensic psychological expertise, aggressiveness is studied as a motivational tendency fixed in a habitual way of reaction in various situations, together along with the personal structures hindering aggressive motives plays a crucial role in the formation of motivation for aggressive actions. ${ }^{14}$

In expert practice, a set of methods is used to study the level of a person's aggressiveness (as a personality trait). That includes standardized questionnaires, projective and semi-projective methods and subjective scaling, which makes it possible to assess the level of readiness for aggressive reactions from the point of view of not only rational self-esteem, but also tendencies less realized by the subject. In the practice of forensic examinations, different methods have proven to be effective in detecting a person's aggressiveness (among other individual psychological

11 Encyclopedia of mental health, ed. H. Friedman, Oxford 2015.

12 B.J. Bushman, C.A. Anderson, "Is it time to pull the plug on the hostile versus instrumental aggression dichotomy?", Psychological Review 2001, no. 108, pp. 273-279.

13 J. Heckhausen, H. Heckhausen, Motivation und Handeln, Berlin 2018.

14 F.S. Safuanov, Psichologija kriminal'noj agressii, Smysl 2003. 
features): MMPI, 16PF, questionnaires of Sobchik, Shmishek, Strelyau, Lichko, Bass-Darky, Spilberg, Rosenzweig, Rotter, drawing tests, Zsondi test, and some others. However, all of them require the investigated person to be involved.

Handwriting psychology could be very useful for evaluating a person's aggressiveness. It cannot distinguish between fine aspects of aggressiveness, but allows detecting the tendency and comparing it with other people. We demonstrate aggressiveness modelling on the example of seven famous American criminals whose aggressivity arouses no doubts. ${ }^{15}$ Charles Luciano (CL, 1897-1962), John Hinckley (JH, 1955-), Charles Manson (CM, 1934-2017), Clyde Barrow (CB, 1909-1934), John Dillinger (JD, 1903-1934), John Gotti (JG, 1940-2002), and Joseph Valachi (JV, 1904-1971). Aggressiveness in HSDetect is modelled by 31 handwriting signs. The results of the handwriting evaluation for the named persons is presented in Table 1, where the handwriting signs are given according to their weight $\left(a_{i}\right)$.

Table 1. Handwriting evaluation for aggressiveness

\begin{tabular}{|l|c|c|c|c|c|c|c|}
\hline \multicolumn{1}{|c|}{ Sign name } & CL & JH & CM & CB & JD & JG & JV \\
\hline Angular connections & $\mathrm{x}$ & $\mathrm{x}$ & $\mathrm{x}$ & $\mathrm{x}$ & $\mathrm{x}$ & $\mathrm{x}$ & $\mathrm{x}$ \\
\hline Strong pressure & $\mathrm{x}$ & - & $\mathrm{x}$ & $\mathrm{x}$ & $\mathrm{x}$ & $\mathrm{x}$ & - \\
\hline Long in-stroke & $\mathrm{x}$ & - & $\mathrm{x}$ & $\mathrm{x}$ & - & - & $\mathrm{x}$ \\
\hline Tapering end-stroke & - & $\mathrm{x}$ & - & - & $\mathrm{x}$ & - & $\mathrm{x}$ \\
\hline $\begin{array}{l}\text { End-stroke goes backwards under } \\
\text { the word }\end{array}$ & - & - & $\mathrm{x}$ & - & - & - & - \\
\hline Elongated letter form & $\mathrm{x}$ & $\mathrm{x}$ & $\mathrm{x}$ & - & $\mathrm{x}$ & $\mathrm{x}$ & - \\
\hline $\begin{array}{l}\text { Signature is surrounded with } \\
\text { enrichments or circle }\end{array}$ & - & - & $\mathrm{x}$ & - & - & - & - \\
\hline Additional hooks on stroke ends & - & - & $\mathrm{x}$ & - & - & - & - \\
\hline Last letters are accented & - & - & $\mathrm{x}$ & $\mathrm{x}$ & $\mathrm{x}$ & - & - \\
\hline $\begin{array}{l}\text { Upper zone is diminished or does } \\
\text { not exist }\end{array}$ & - & - & - & - & - & - & - \\
\hline
\end{tabular}

15 Y. Chernov, V. Engalychev, op. cit. 


\begin{tabular}{|c|c|c|c|c|c|c|c|}
\hline $\begin{array}{l}\text { I-points are arrow- or comma- } \\
\text { shaped }\end{array}$ & $\mathrm{x}$ & $\mathrm{x}$ & $\mathrm{x}$ & - & - & $\mathrm{x}$ & - \\
\hline $\begin{array}{l}\text { Lower zone is angular or has } \\
\text { triangle-shaped }\end{array}$ & - & - & - & $\mathrm{x}$ & - & $\mathrm{x}$ & - \\
\hline Capital letters are very small & - & - & - & - & - & - & - \\
\hline Lower loops are not closed & $\mathrm{x}$ & - & $\mathrm{x}$ & - & - & $\mathrm{x}$ & $\mathrm{x}$ \\
\hline Letters are broken & - & $\mathrm{x}$ & $\mathrm{x}$ & - & $\mathrm{x}$ & - & - \\
\hline Diacritic marks are irregular & - & $\mathrm{x}$ & $\mathrm{x}$ & - & - & $\mathrm{x}$ & - \\
\hline Signature is larger than text & $\mathrm{x}$ & $\mathrm{x}$ & - & - & - & - & - \\
\hline $\begin{array}{l}\text { Pressure is stronger on vertical } \\
\text { strokes }\end{array}$ & $\mathrm{x}$ & $\mathrm{x}$ & $\mathrm{x}$ & $\mathrm{x}$ & $\mathrm{x}$ & $\mathrm{x}$ & - \\
\hline $\begin{array}{l}\text { Middle zone is smaller than upper } \\
\text { and lower zones }\end{array}$ & $\mathrm{x}$ & $\mathrm{x}$ & $\mathrm{x}$ & $\mathrm{x}$ & $\mathrm{x}$ & $\mathrm{x}$ & $\mathrm{x}$ \\
\hline Sharp strokes & $\mathrm{x}$ & $\mathrm{x}$ & $\mathrm{x}$ & - & - & $\mathrm{x}$ & - \\
\hline $\begin{array}{l}\text { Upper and lower loops overlap } \\
\text { allied lines }\end{array}$ & $\mathrm{x}$ & $\mathrm{x}$ & $\mathrm{x}$ & $\mathrm{x}$ & - & $\mathrm{x}$ & $\mathrm{x}$ \\
\hline Connected handwriting & $\mathrm{x}$ & $\mathrm{x}$ & $\mathrm{x}$ & $\mathrm{x}$ & $\mathrm{x}$ & $\mathrm{x}$ & $\mathrm{x}$ \\
\hline Quick handwriting & $\mathrm{x}$ & $\mathrm{x}$ & $\mathrm{x}$ & $\mathrm{x}$ & - & - & $\mathrm{x}$ \\
\hline Poor arrangement & $\mathrm{x}$ & $\mathrm{x}$ & $\mathrm{x}$ & $\mathrm{x}$ & - & $\mathrm{x}$ & $\mathrm{x}$ \\
\hline Stronger pressure on diacritic marks & $\mathrm{x}$ & - & - & - & $\mathrm{x}$ & $\mathrm{x}$ & - \\
\hline $\begin{array}{l}\text { Back-stroke of lower zone is on } \\
\text { right from the base stroke }\end{array}$ & - & - & - & - & - & - & - \\
\hline Poor readability & - & - & - & - & - & - & - \\
\hline Left margin is widening & - & - & $\mathrm{x}$ & - & - & - & - \\
\hline First letters are accented & - & - & $\mathrm{x}$ & - & - & - & - \\
\hline Uneven distribution of pressure & $\mathrm{x}$ & $\mathrm{X}$ & $\mathrm{X}$ & $\mathrm{x}$ & $\mathrm{x}$ & $\mathrm{x}$ & $\mathrm{x}$ \\
\hline $\begin{array}{l}\text { Lower loops are transformed in } \\
\text { plane lines without back-stroke }\end{array}$ & - & $\mathrm{X}$ & - & - & - & $\mathrm{X}$ & $\mathrm{X}$ \\
\hline
\end{tabular}

To make the interpretation easier let us use the plain P-model. According to it, the absolute aggressiveness level for the evaluated persons $(y)$ looks as follows: $\mathrm{CL}-0.52, \mathrm{JH}-0.52, \mathrm{CM}-0.71, \mathrm{CB}-0.39, \mathrm{JD}-0.35$, $\mathrm{JG}-0.52$, and JV -0.35 . The statistical mean value $(m)$ based on the HSDetect database is 0.19 with the standard deviation $(\sigma) 0.09$. This means that the $99 \%$ level $(m+3 \sigma)$ is reached at 0.46 and the $95 \%$ level $(m+2 \sigma)$ at 0.37 . Therefore, four out of seven persons have an extremely high level 
of aggressivity and the remaining three - a very high one. That closely corresponds with our expectations.

\section{Use case 2: Assessment of credibility}

Credibility is another important trait, or more precisely a construct, since it actually reflects several traits. To what extent different participants of an investigation and a trial can be trusted? The construct is very important not only in the criminal environment, but also in business. Actually, what is more interesting is the opposite side of the spectrum non-credibility.

The experiment was done with students in one of the St. Petersburg military universities(the complete results of the experiments are not published yet). Experts (17 lecturers) evaluated 70 students whom they had known for several years. That means every student received 17 opinions about their credibility. Some evaluations could not demonstrate good interrater reliability. Thus, we took 24 absolutely clear cases with the strongest agreement among experts: 12 with the highest credibility (group A) and 12 with the lowest one (group B). The handwriting evaluations were done according to the HSDetect model (Table 2).

Table 2. Handwriting evaluation for credibility

\begin{tabular}{|c|c|c|}
\hline Handwriting sign & Incredibility & Credibility \\
\hline Letter intervals & narrow & \\
\hline letter width & & wide letters \\
\hline Lines & letter zones intersect & \\
\hline Slant & left or direct & right \\
\hline Letter form & $\begin{array}{l}\text { threading } \\
\text { complicated with additional and } \\
\text { rolling elements } \\
\text { terminal letters are wavy or bend }\end{array}$ & simplified \\
\hline Capital letters & complicate form & simple, print form \\
\hline Handwriting form & $\begin{array}{l}\text { disordered with distorted or broken } \\
\text { letters } \\
\text { corrections and striking out } \\
\text { missing some letters and letter } \\
\text { elements }\end{array}$ & angular or garland \\
\hline
\end{tabular}




\begin{tabular}{|l|l|l|}
\hline Connections & $\begin{array}{l}\text { thread or arcade } \\
\text { not stable, changing } \\
\text { joins }\end{array}$ & \\
\hline Fullness & full handwriting & strong \\
\hline Pressure & weak & high \\
\hline Speed & low & $\begin{array}{l}\text { closed, simple form } \\
\text { open at top }\end{array}$ \\
\hline Ovals & $\begin{array}{l}\text { closed with loop } \\
\text { open at bottom }\end{array}$ & covering strokes \\
\hline Strokes & connected to a neighbour letter & moved to the right \\
\hline Diacritic signs & dominating form & \\
\hline Form-Dymanics relation & &
\end{tabular}

Based on the handwriting analysis, we inquired whether it is credibility or incredibility that dominates among the subjects. In group A, in 9 out of 12 handwriting samples the dominance of credibility was detected. In group B, incredibility was dominating in 10 subjects. Thus, the agreement with the experts is obviously quite high, much higher than a chance coincidence.

\section{Discussion}

The presented examples illustrated the possibilities of the handwriting psychology in legal psychological assessments. International standards for the assessment methods in legal psychology are unknown to us. However, we can orient ourselves in the corresponding standards of organisation psychology. ${ }^{16}$ The proposed procedure of formalised handwriting psychology supported by HSDetect meets the standard requirements. It is formal, unambiguous, and transparent. Thus, we can say that it meets the required quality level. HSDetect provides a qualitative framework for implementing the method. However, a good procedure alone does not assure satisfactory results. Currently, the HSDetect model is based on the statistically balanced, but still traditional graphological rules. We know

16 ISO 10667-2:2020. Assessment service delivery - Procedures and methods to assess people in work and organizational settings - Part 2: Requirements for service providers. 
that in certain cases, i.e. for certain traits and constructs, they work well their validity was proven by the corresponding studies. However, that does not mean that the models for other traits are automatically valid as well. That should be properly evaluated and the models (graphometric functions) adapted based on real legal cases, experiments, and further statistical evaluations. Nevertheless, handwriting psychology has proven its usefulness in certain cases, even today.

\section{References}

Baron R.A., Richardson D., Human aggression, New York 1994.

Ben-Shakhar et al., "Can graphology predict occupational success? Two empirical studies and some methodological ruminations", Journal of Applied Psychology 71, 1986, no. 4.

Bushman B.J., Anderson C.A., "Is it time to pull the plug on the hostile versus instrumental aggression dichotomy?", Psychological Review 2001, no. 108.

Chamorro-Premuzic T., Furnham A., The psychology of personnel selection, Cambridge 2014.

Chernov Y., "Der Einsatz des Computers in der Graphologie", Angewandte Graphologie und Persönlichkeitsdiagnostik 2014, no. 2.

Chernov Y., "Formal modelling of projective techniques and their validation", paper presented at the $82^{\text {nd }}$ Annual Meeting of the Psychometric Society (IMPS 2017), Zurich, Switzerland, 17-21 July 2017.

Chernov Y., "Formal validation of handwriting analysis", [in:] Handwriting research: Validation \& quality, Berlin 2018.

Chernov Y., Psychologicheskij analiz pocherka. Sistemnij podhod, Moscow 2011.

Chernov Y., "Validation of computer-aided handwriting analysis and its integration into psychological assessment", paper presented at the $15^{\text {th }}$ European Conference on Psychological Assessment (ECPA 15), Brussels, Belgium, 7-10 July 2019.

Chernov Y., Caspers C., "Computergestützte Validierung in der Graphologie", Angewandte Graphologie und Persönlichkeitsdiagnostik 2015, no. 2-3.

Chernov Y., Caspers C., "Formalized computer-aided handwriting psychology: Validation and integration into psychological assessment", Behavioral Sciences 10, 2020, no. 1.

Chernov Y., Caspers C., "Formalized computer-aided handwriting analysis: Validation and integration into psychological assessment", paper presented at the XVI European Congress of Psychology, Moscow, Russia, 2-5 July 2019.

Chernov Y., Engalychev V., "Distant profiling: Aggression evaluation with formalized handwriting analysis", Armenian Journal of Forensic Expertise and Criminalistics, 2019, no. 1 .

Chernov Y., Engalychev V., "Formal handwriting analysis as an instrument for forensic and criminal psychology", Armenian Journal of Mental Health 9, 2018, no. 1. 
Dazzi C., Pedrabissi L., "Graphology and personality: An empirical study on validity of handwriting analysis", Psychological Reports 105, 2009, no. 3.

Encyclopedia of mental health, ed. H. Friedman, Oxford 2015.

Engalychev V., "The place of handwriting analysis in legal psychology: Topical issues and research perspectives", Aspects of Handwriting 2020, no. 2, https://issuu.com/ aspectsofhandwriting/docs/aspects_of_handwriting_issue_2.

Engalychev V., Chernov Y., "Psychological profiling with the support of formal handwriting analysis", paper presented at the XVI European Congress of Psychology, Moscow, Russia, 2-5 July 2019.

Eysenck H.J., Guidjonsson G., "An empirical study of the validity of handwriting analysis", Personality and Individual Differences 7, 1986, no. 2.

Furnham A., Chamorro-Premuzic T., Callahan I., "Does graphology predict personality and intelligence?", Individual Differences Research 1, 2003, no. 2.

Furnham A., Gunter B., "Graphology and personality: Another failure to validate graphological analysis", Personality and Individual Differences 8, 1987, no. 3.

Gawda B., "Lack of evidence for the assessment of personality traits using handwriting analysis", Polish Psychological Bulletin 45, 2014, no. 1.

Heckhausen J., Heckhausen H., Motivation und Handeln, Berlin 2018.

Howitt D., Introduction to forensic and criminal psychology, Harlow 2018.

ISO 10667-2:2020. Assessment service delivery - Procedures and methods to assess people in work and organizational settings - Part 2: Requirements for service providers.

Kanning U.P., Standards der Personaldiagnostik, Göttingen 2019.

King R.N., Koehler D.J., "Illusory correlation in graphological inference", Journal of Experimental Psychology 5, 2000, no. 4.

Klimoski R., Rafaeli A., "Inferring personal qualities through handwriting analysis", Journal of Occupational Psychology 56, 1983, no. 3.

Nauer M.A., Chernov Y., "Psychodynamic diagnostics - validation research based on computer modelling of handwriting psychology", paper presented at the $13^{\text {th }}$ European Conference on Psychological Assessment (ECPA 13), Zurich, Switzerland, 22-25 July 2015.

Netter E., Ben-Shakhar G., "The predictive validity of graphological inferences: A meta-analytic approach", Personality and Individual Differences 10, 1989, no. 7.

Safuanov F.S., Psichologija kriminal'noj agressii, Smysl 2003.

Vestewig R., Moss M., "On the validity of graphoanalysis", Journal of Personality Assessment 41, 1977. 